\title{
Congenital cystic adenomatoid malformation associated with right aortic arch with mirror image branching and absence of left pulmonary artery in an adult
}

Elamparidhi Padmanaban, Kamala Manogna Nibhanupudi* ${ }^{*}$, Umamageswari Amirthalingam,

Padma Rekha and Rintu George

\begin{abstract}
Background: Congenital cystic adenomatoid malformation is an uncommon developmental anomaly that is diagnosed prenatally or during early childhood and is rare to present in adulthood. Type 2 congenital cystic adenomatoid malformation is often associated with other anomalies such as congenital cardiac anomalies. We present a case of type 2 congenital cystic adenomatoid malformation in an adult male associated with absence of left pulmonary artery and right aortic arch with mirror image branching. To our knowledge, this is the first case report with the combination of all three anomalies.

Case presentation: A 33-year-old male presented to the Department of Pulmonary Medicine with high-grade fever, chills and rigor, breathlessness, and productive cough for a duration of one week. He had multiple similar self-limiting episodes in the past which did not require hospitalization. The plain radiograph showed right aortic arch and a small left hilum. CT thorax showed multiple cystic lesions of size $0.5-2.0 \mathrm{~cm}$ in the apico-posterior segment of the left upper lobe; anterior, posterior, and lateral segments of the left lower lobe; and the apical segment of the right upper lobe with a maximal cyst wall thickness of $2 \mathrm{~mm}$. Volume of left lung was reduced with trans-thoracic herniation of the medial segment of the right middle lobe; bronchiectatic changes were seen in the apical, anterior, and posterior segments of the right upper lobe; and fibrotic strands were seen in the apical segment of the right lower lobe and the apico-posterior segment of the right upper lobe. Mediastinal window showed right-sided aortic arch with mirror image branching. The pulmonary trunk was seen to continue as the right pulmonary artery with absent left pulmonary artery.
\end{abstract}

Conclusions: Though congenital cystic adenomatoid malformation is a disease of infancy and childhood, it should also be considered in adults presenting with recurrent lower respiratory tract infections and/or pneumothorax. Radiologists must be aware of the types of congenital cystic adenomatous malformation (CCAM) and their associations, as type 2 CCAM has a high association with congenital cardiac disease. Proximal interruption of pulmonary artery should be considered if the pulmonary trunk continues as either right or left pulmonary artery.

Keywords: Congenital cystic adenomatoid malformation, Absence of pulmonary artery, Unilateral absence of pulmonary artery, Right aortic arch with mirror image branching, Case report

\footnotetext{
*Correspondence: kamalamanogna10@gmail.com

Department of Radio-Diagnosis, Sri Manakula Vinayagar Medical College

and Hospital, Kalitheerthalkuppam, Madagadipet, Puducherry 605107,

India
}

(c) The Author(s) 2021. Open Access This article is licensed under a Creative Commons Attribution 4.0 International License, which permits use, sharing, adaptation, distribution and reproduction in any medium or format, as long as you give appropriate credit to the original author(s) and the source, provide a link to the Creative Commons licence, and indicate if changes were made. The images or other third party material in this article are included in the article's Creative Commons licence, unless indicated otherwise in a credit line to the material. If material is not included in the article's Creative Commons licence and your intended use is not permitted by statutory regulation or exceeds the permitted use, you will need to obtain permission directly from the copyright holder. To view a copy of this licence, visit http://creativecommons.org/licenses/by/4.0/. 


\section{Background}

Congenital cystic adenomatoid malformation is an uncommon developmental anomaly that is diagnosed prenatally or during early childhood and is rare to present in adulthood. Type 2 congenital cystic adenomatoid malformation is associated with other anomalies such as congenital cardiac anomalies. We present a case of type 2 congenital cystic adenomatoid malformation in an adult male associated with absence of left pulmonary artery and right aortic arch with mirror image branching. To our knowledge, this is the first case report with the combination of all three anomalies.

\section{Case presentation}

A 33-year-old male presented to the Department of Pulmonary Medicine with high-grade fever, chills and rigor, breathlessness, and productive cough for a duration of one week. He had multiple similar self-limiting episodes in the past which did not require hospitalization. He was not aware of any neonatal intensive care admissions. He did not have any comorbidities such as diabetes mellitus, hypertension, tuberculosis, bronchial asthma, or occupational lung disease. He had no previous history of allergies. His general status and blood investigations were normal. On auscultation, crepitations were noted in the left mammary region. The plain radiograph showed right aortic arch and a small left hilum. CT scan of thorax was performed on a 16-slice Philips CT scanner with the slice thickness of $1 \mathrm{~mm}, \mathrm{~mA}-400, \mathrm{KV}-120$. Post-contrast studies were performed after injecting $80 \mathrm{ml}$ of $300 \mathrm{mg} \mathrm{I} / \mathrm{ml}$ iohexol contrast intravenously. CT thorax showed multiple cystic lesions of size $0.5-2.0 \mathrm{~cm}$ in the apico-posterior segment of the left upper lobe; anterior, posterior, and lateral segments of the left lower lobe; and the apical segment of the right upper lobe with a maximal cyst wall thickness of $2 \mathrm{~mm}$. The left lung showed a reduction in lung volume with trans-thoracic herniation of the medial segment of the right middle lobe (Figs. 1 and 2). Diffuse ground-glass opacities were seen in the left lower lobe. Bronchiectatic changes were seen in the apical, anterior, and posterior segments of the right upper lobe. Fibrotic strands were seen in the apical segment of the right lower lobe and the apico-posterior segment of the right upper lobe. In the mediastinal window, right-sided aortic arch was seen with the right subclavian artery, right common carotid artery, and left brachiocephalic trunk (Fig. 3). The pulmonary trunk was seen to continue as the right pulmonary artery. The left pulmonary artery was absent (Fig. 4). The left internal thoracic and bronchial arteries appeared to be enlarged. Multiple enlarged posterior intercostal collaterals were noted (Figs. 5 and 6). The pulmonary veins appeared normal.

\section{Discussion}

CCAM is the most commonly diagnosed lung malformation in prenatal patients and accounts for $30-40 \%$ of all congenital diseases [1]. The reported incidence of CCAM ranges from 1 in 11,000 to 1 in 35,000 live births, with a higher incidence in the mid-trimester due to spontaneous resolution [2]. CCAM affects both males and females equally. The diagnosis of CCAM is very rare in adults, and only 61 cases have been reported in the literature to date to our knowledge [3, 4]. There are five types of CCAM in which type 2 CCAM is frequently associated with cardiovascular anomalies such as septal defects or tetralogy of Fallot. The exact incidence is, however, not

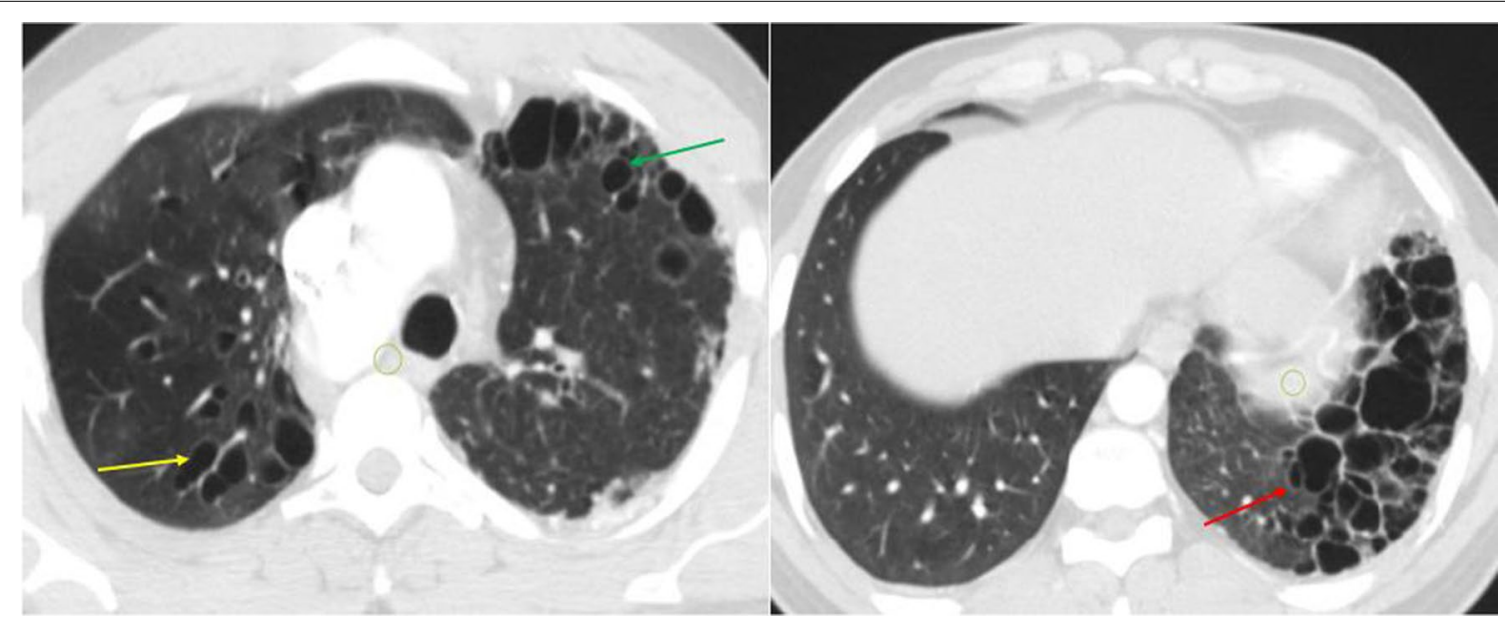

Fig. 1 Axial non-contrast CT thorax at the level of upper and lower lobes demonstrates multiple cysts in cluster with none measuring $>2 \mathrm{cms}$, in the posterior and lateral basal segments of left lower lobe (red arrow) - CCAM type 2. Right upper lobe bronchiectasis (yellow arrow) and left upper lobe anterior segment cysts (green arrow). Loss of left lung volume with trans-thoracic herniation of the medial segment of right lower lobe 


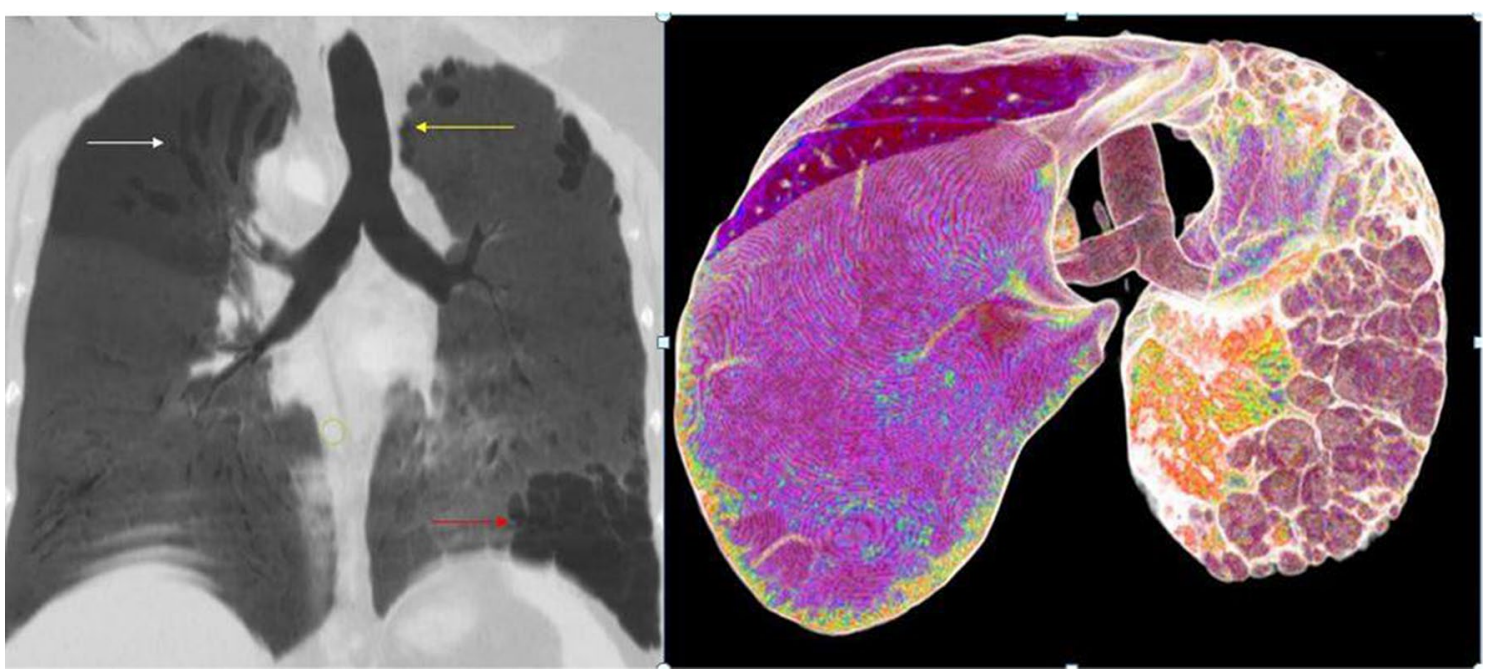

Fig. 2 Non-contrast CT thorax coronal mini IP and volume-rendered basal view of lungs demonstrate cluster of cysts in the left lower lobe (red arrow) and upper lobe (yellow arrow) and tubular bronchiectasis in the right upper lobe (white arrow). Volume-rendered image shows left lower lobe cysts with significant loss of lung volume

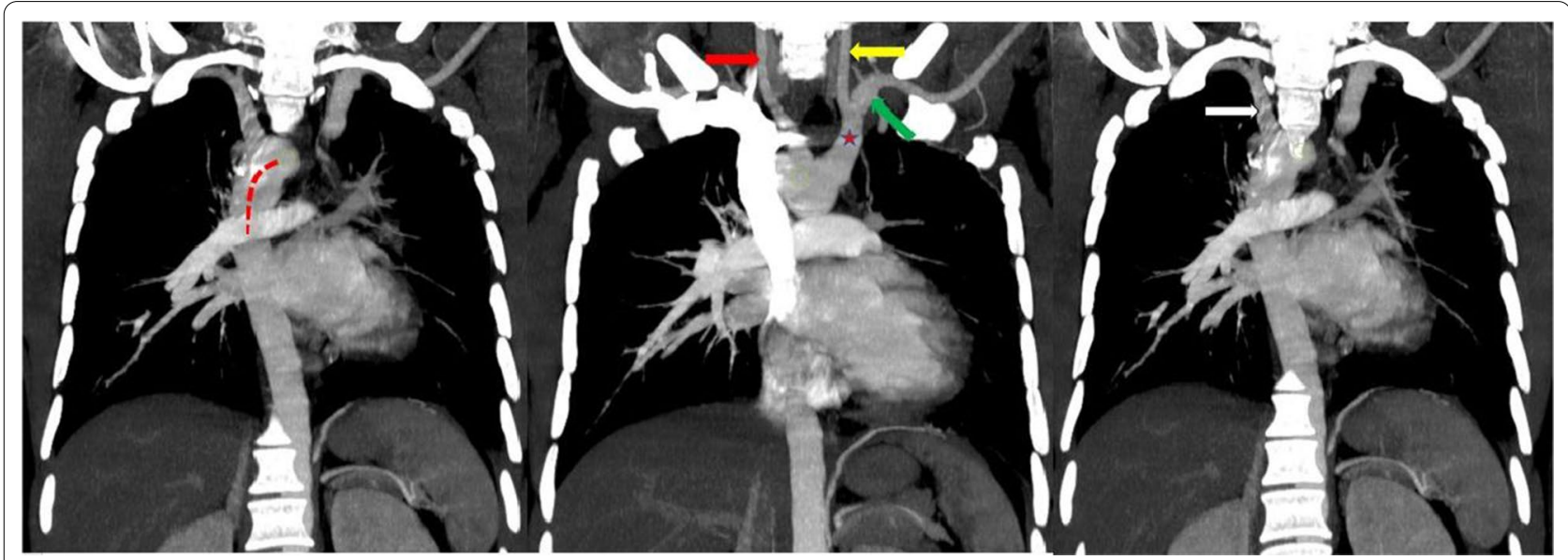

Fig. 3 Coronal MIP post-contrast CT thorax in arterial phase demonstrates right-sided aortic arch (curved dotted red line) with left brachiocephalic trunk (red asterix) dividing into left common carotid artery (yellow arrow), left subclavian artery (green arrow), right common carotid artery (red arrow), and right subclavian artery (white arrow)

reported. To our knowledge, only one case has been reported with the association of unilateral pulmonary artery agenesis in a pediatric patient [5]. As far as we know, not a single case has been reported with this association of type 2 CCAM with absence of left pulmonary artery and right aortic arch with mirror branching, both of which are not very common when both entities considered separately. Unilateral absence of the pulmonary artery (UAPA) is a very rare congenital malformation with a prevalence of $0.0005 \%$. It is more often associated with other congenital cardiac defects such as aortic coarctation, tetralogy of Fallot, and right aortic arch but can occur in a isolated manner. UAPA is more common on the right side $[6,7]$. The right aortic arch is a rare congenital defect of the aorta and is seen in $0.05 \%$ to $0.1 \%$ of adult radiology series and 0.04 to $0.1 \%$ of autopsy series [8]. Congenital heart anomalies such as TOF, pulmonary stenosis with ventricular septal defect, tricuspid atresia, and truncus arteriosus are present in $75-85 \%$ in type I and type III and in $5-10 \%$ in type II RAA [9]. The exact incidence of RAMI is not found in the literature as most of these cases go undetected (Fig. 7). 


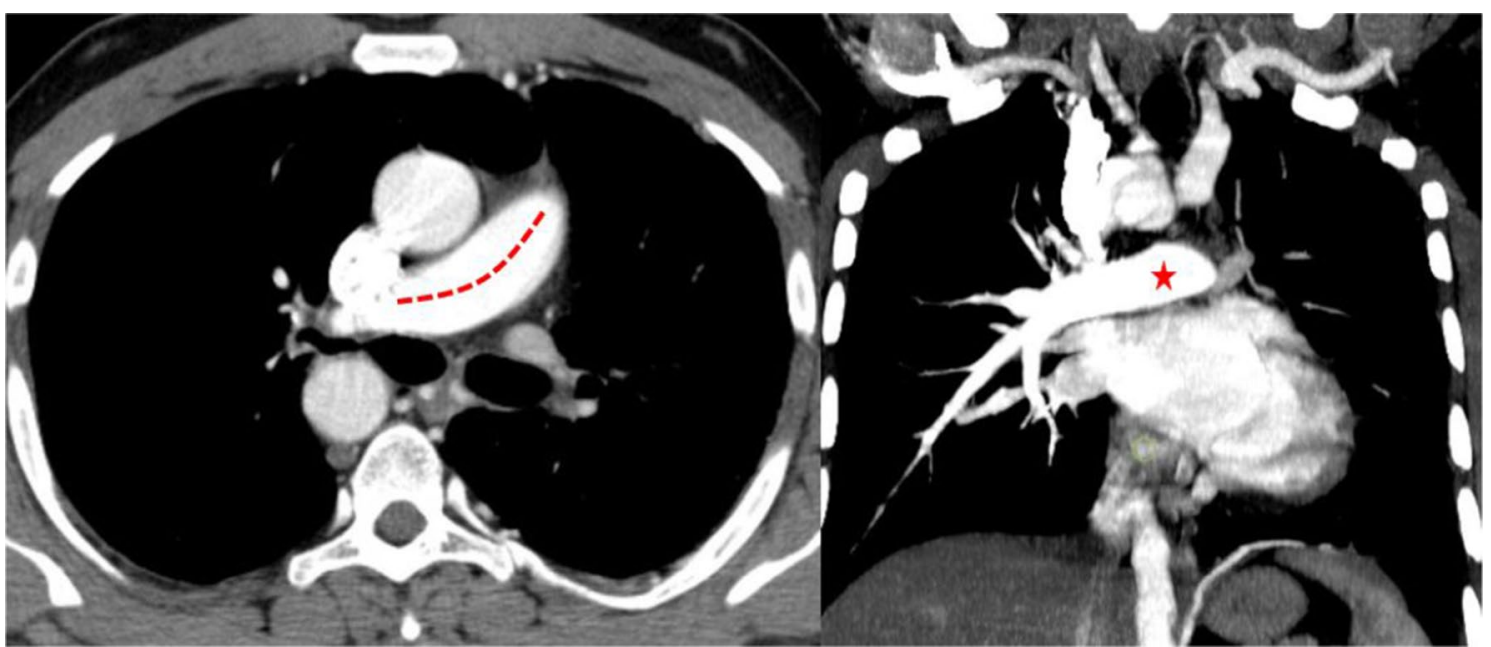

Fig. 4 Axial and coronal MIP post-contrast CT thorax in arterial phase demonstrates direct continuation of pulmonary artery trunk as the right main pulmonary artery (curved dotted line and asterix). Left pulmonary artery is not seen from the origin. Paucity of vessels is seen in the left lung when compared to the right

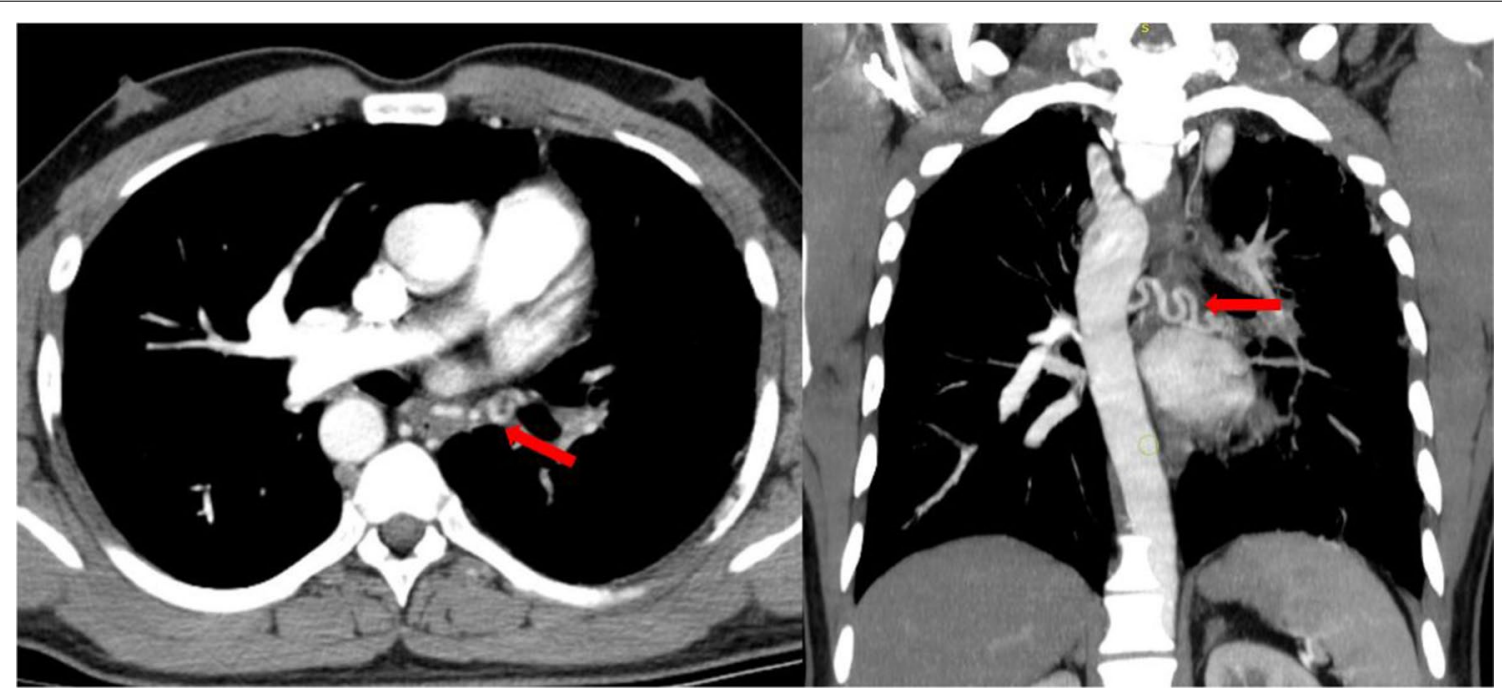

Fig. 5 Axial and coronal MIP post-contrast CT thorax in arterial phase demonstrates dilated bronchial artery seen from the descending thoracic aorta (red arrow)

\section{Clinical and imaging findings}

The classification of CCAM has evolved over the years, and there are five types-type 0 (previously described as acinar dysplasia), type 1 (macrocystic $>2 \mathrm{~cm}$ ), type 2 (multiple smaller cysts), type 3 (solid with microscopic cysts), and type 4 (a type of peripheral lung disease manifesting as pneumothorax); neither cystic nor adenomatoid lesions were always present [10]. Furthermore, hybrid lesions that seem to combine features of CCAM and pulmonary sequestration also have been found to occur. Type 1 is the most common form, with a frequency of $50 \%$ to $70 \%$. In chest radiography, large, unilateral, airfilled, multicystic lesions will be seen in the lung with progressive respiratory distress. Type 2 is seen in $15 \%$ to $30 \%$ and is composed of various smaller cysts $(0.5-2 \mathrm{~cm})$. In chest radiograph, there will be heterogeneous areas of uniform small cysts and appears predominantly radiopaque. Prognosis depends on associated anomalies and the extent of lung involvement. Type 3 occurs in $5 \%$ to $10 \%$ and consists of small cystic lesions that are rarely larger than $0.2 \mathrm{~cm}$ in diameter. Radiograph shows a large homogeneous lesion giving the appearance of 


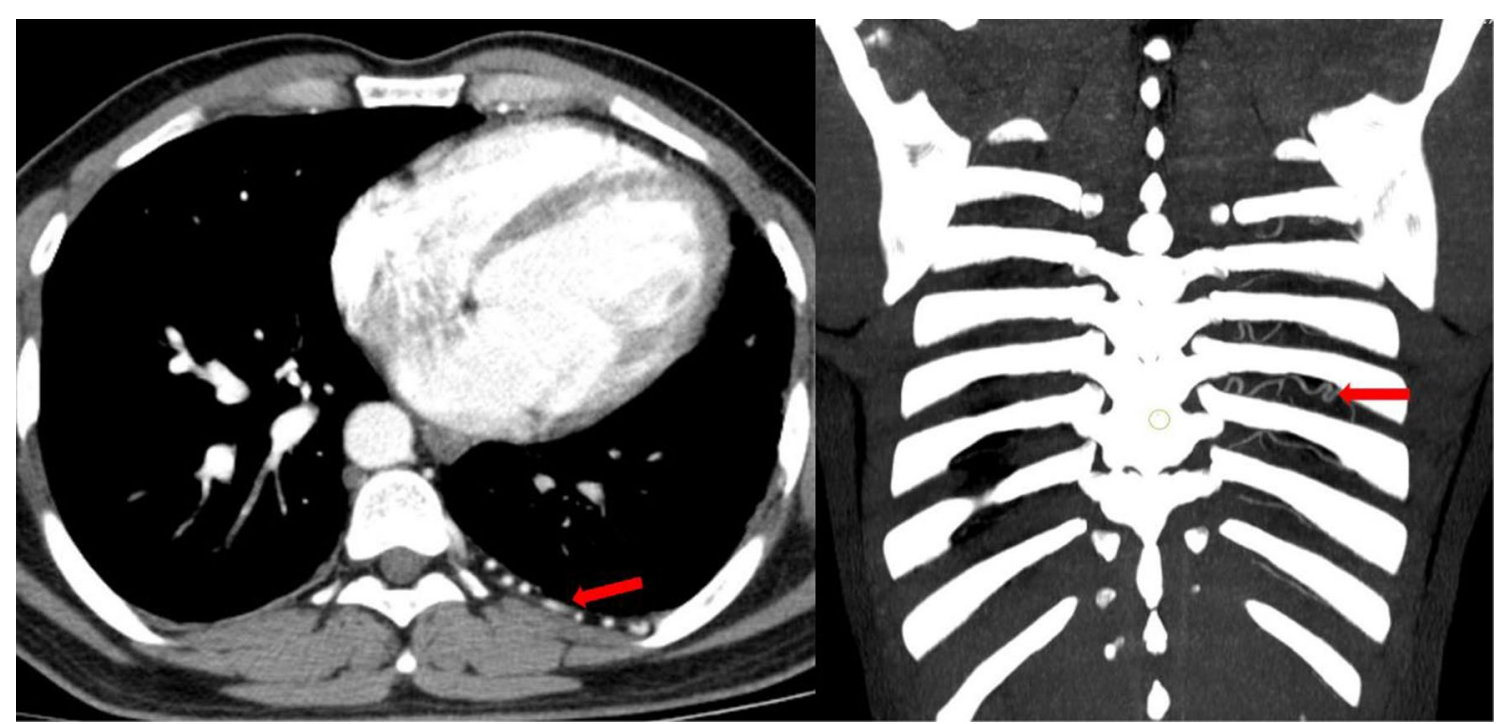

Fig. 6 Axial and coronal MIP post-contrast CT thorax in arterial phase demonstrates dilated tortuous posterior intercostal arteries on the left side (red arrow)

consolidation or a mass. The CT findings of CCAM vary depending on the subtype. Type 1 lesions usually manifest as hyperintense uni- or multilocular regions with discrete walls on T2-weighted images. Type 2 lesions have variable appearances depending on the composition of the malformation. Type 3 lesions manifest as homogeneously hyperintense solid masses with normal adjacent parenchyma. Type 0 shows smaller cysts, and the presentation is severe and is usually lethal. Type 4 has findings similar to type 1 and has larger cysts up to $10 \mathrm{~cm}$ [11].

UAPA is a rare condition which commonly occurs in conjunction with cardiovascular abnormalities such as tetralogy of Fallot or cardiac septal defects, but can also present in an isolated manner [12, 13]. UAPA involves the right lung in about two-thirds of cases and commonly occurs on the side of the chest opposite the aortic arch [10]. The chest radiograph typically shows an ipsilateral small hemithorax with mediastinal shift toward the affected side and small hilum [12]. The contralateral lung may be hyperinflated and appear plethoric due to increased blood flow. On cross-sectional imaging, the absent pulmonary artery will typically terminate within $1 \mathrm{~cm}$ of its expected origin from the main pulmonary artery [12]. Other findings on CT or MRI are variable collateral circulation, mosaic parenchymal changes, and bronchiectasis secondary to recurrent infections $[12,14$, 15]. Angiography is considered the gold standard for the diagnosis of UAPA. However, it is not generally necessary for diagnosis unless it is being used as a preoperative test for a patient who has developed hemoptysis or severe infection.
RAMI is mostly asymptomatic and is usually an incidental radiological finding. In adults, RAMI can produce symptoms as a result of atherosclerotic changes in the anomalous vessels or aneurysmal dilatation accompanied by compression over adjacent structures such as the trachea and esophagus presenting as dysphagia lusoria or respiratory distress. In RAMI, the left innominate artery is the first branch arising from the arch, followed by the right carotid artery and the right subclavian artery. In RAA with ALSA, the first branch from the aortic arch is the left carotid artery, followed by the right carotid artery, right subclavian artery, and ALSA. In RAA with the isolation of the left subclavian artery, the first branch is the left carotid artery, followed by the right carotid and right subclavian arteries [16].

Our case showed multiple uniform small-sized cysts in both the lungs, suggestive of type 2 CCAM, right aortic arch with mirror image branching, as well as absence of mediastinal segment of left pulmonary artery with paucity of pulmonary vessels in the left lung and dilated systemic collaterals which were consistent with absence of left pulmonary artery.

The differential diagnoses for CCAM include SwyerJames-Macleod syndrome, bronchopulmonary sequestration, bronchogenic cyst, cystic bronchiectasis, lymphangiomyomatosis, Langerhans cell histiocytosis, and centrilobular emphysema.

\section{Treatment and prognosis}

Prenatally, fetal therapies for CCAM such as needle aspiration, catheter shunt placement, and fetal surgical 


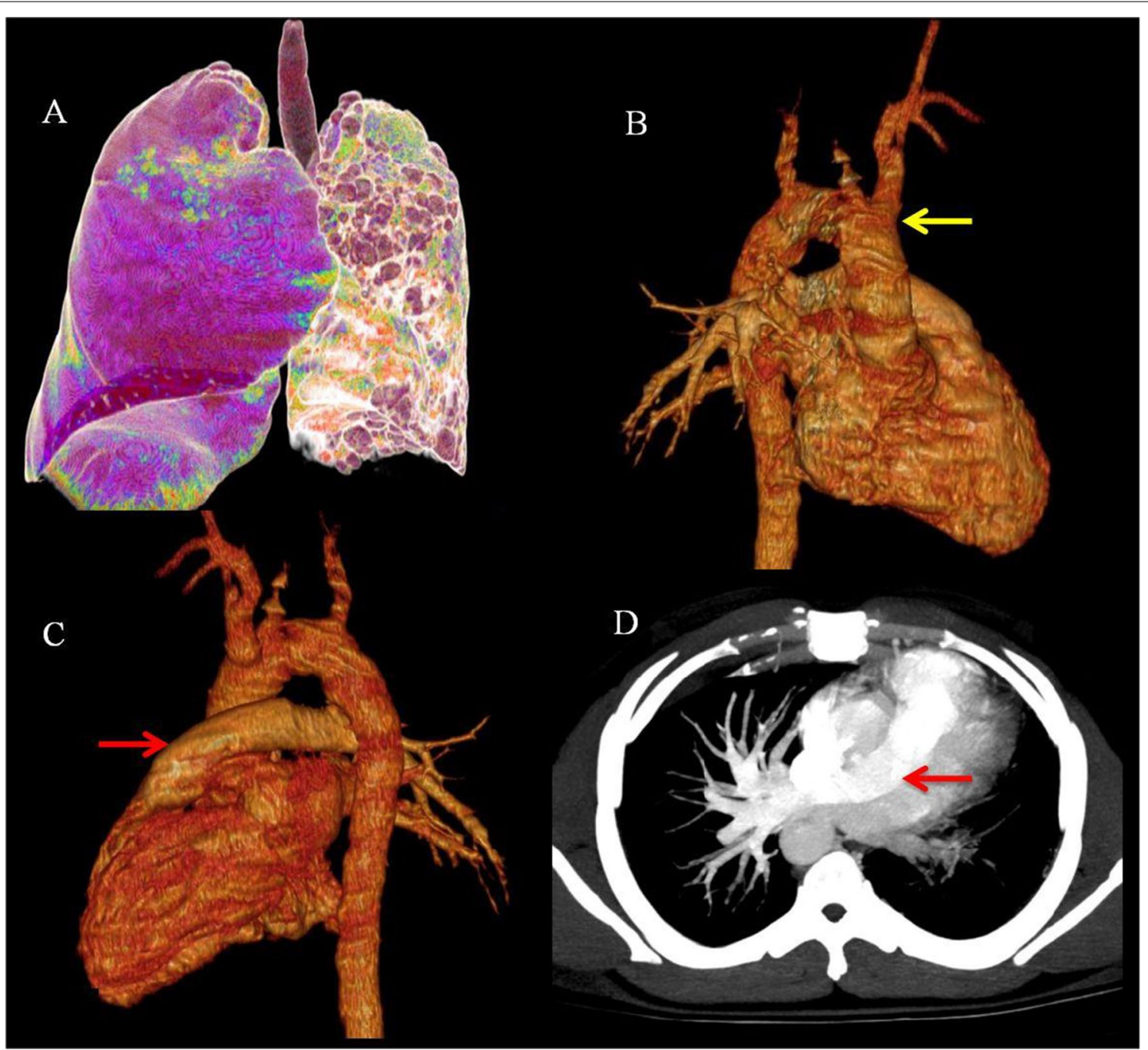

Fig. 7 a Multiple cysts in cluster in the left lung involving upper and lower lobes with loss of volume-CCAM. b Right aortic arch with mirror image branching (yellow arrow). c, d Pulmonary trunk continuing as right pulmonary artery (red arrow) - absence of left pulmonary artery

resection may be applied. Postnatally, the cysts in CCAM have the risk of repeated infections and may go for malignant transformation to adenocarcinoma. Hence, lobectomy should be performed even if the patient is asymptomatic. Two major factors affect the management of congenital cystic lung disease after birth: the timing of respiratory decompensation and the presence of any associated complications. When lobectomy is done in asymptomatic patients, they showed a significant reduction in the incidence of complications and duration of hospital stay when compared to the patients who have not undergone surgery. Post-surgical follow-up is done using CT chest and pulmonary function tests.

Cases of UAPA complicated by hemoptysis, recurrent pulmonary infections, or intractable pulmonary hypertension necessitate intervention. Transcatheter embolization of aortopulmonary collaterals, either alone or as an adjunct to surgery, is safe and effective.

\section{Conclusions}

Though congenital cystic adenomatoid malformation is a disease of infancy and childhood, it should also be considered in adults presenting with recurrent lower respiratory tract infections and/or pneumothorax. Radiologists must be aware of the types of CCAM and their associations as type 2 CCAM has a high association with congenital cardiac disease. PIPA should be considered if the pulmonary trunk continues as either right or left pulmonary artery. 


\section{Abbreviations}

CCAM: Congenital cystic adenomatous malformation; RAA: Right aortic arch; RAMI: Right aortic arch with mirror imaging; UAPA: Unilateral absence of pulmonary artery; TOF: Tetralogy of Fallot; MRI: Magnetic resonance imaging; CT: Computed tomography; MDCT: Multi-detector computed tomography.

\section{Acknowledgements}

None.

\section{Authors' contributions}

EP was involved in identification of the imaging findings, diagnosed the condition, and helped in manuscript preparation; KMN collected data including image retrieval and prepared the manuscript; UA gave expert opinion on the imaging features, discussed differentials, and contributed to manuscript preparation; PR helped in diagnosing the condition and provided literature search, followed by refining the manuscript; and RG helped in refining the manuscript and identified the radiographic findings. All the authors have participated sufficiently in contributing to the content of 'congenital cystic adenomatoid malformation associated with right aortic arch with mirror image branching and absence of left pulmonary artery in an adult' and have read and approved the manuscript.

\section{Funding}

None.

\section{Availability of data and materials}

Available.

\section{Declarations}

\section{Ethics approval and consent to participate}

Ethical approval is not obtained, since it is a retrospective case report. Informed written consent had been obtained from the participant for participation and publication of the same as a case report.

\section{Consent for publication}

Informed written consent had been obtained from the participant for publication of the same as a case report.

\section{Competing interests}

The authors declare no competing interests.

Received: 1 June 2021 Accepted: 1 September 2021

Published online: 14 September 2021

\section{References}

1. Daltro P, Fricke BL, Kline-Fath BM et al (2005) Prenatal MRI of congenital abdominal and chest wall defects. AJR Am J Roentgenol 184(3):1010-1016

2. Gornall AS, Budd JL, Draper ES, Konje JC, Kurinczuk JJ (2003) Congenital cystic adenomatoid malformation: accuracy of prenatal diagnosis, prevalence and outcome in a general population. PrenatDiagn 23(12):9971002. https://doi.org/10.1002/pd.739
3. Hamanaka R, Yagasaki H, Kohno M, Masuda R, Iwazaki M (2018) Congenital cystic adenomatoid malformation in adults: report of a case presenting with a recurrent pneumothorax and a literature review of 60 cases. Respir Med Case Rep 26:328-332. https://doi.org/10.1016/j.rmcr.2018.02. 002

4. Xu W, Wen Q, Zha L, Liu C, Huang P (2020) Application of ultrasound in a congenital cystic adenomatoid malformation in an adult: a case report. Medicine (Baltimore) 99(49):e23505. https://doi.org/10.1097/MD.00000 00000023505

5. David JJ, Mohanlal S, Sankhe P, Ghildiyal R (2016) Unilateral right pulmonary artery agenesis and congenital cystic adenomatoid malformation of the right lung with Ortner's syndrome. Lung India 33(5):553-555. https:// doi.org/10.4103/0970-2113.188982

6. Anisau A, Vanhoenacker F, Pilate I (2018) Unilateral absence of the pulmonary artery. J Belgian Soc Radiol 102(1):75. https://doi.org/10.5334/jbsr. 1611

7. Lee CH, Son JW, Park JS (2004) Comprehensive three-dimensional analysis of right-sided aortic arch with multiple vascular anomalies. BMC Cardiovasc Disord 14:104

8. Cinà CS, Althani H, Pasenau J, Abouzahr L (2004) Kommerell's diverticulum and right-sided aortic arch: a cohort study and review of the literature. J Vasc Surg 39(1):131-139. https://doi.org/10.1016/j.jvs.2003.07. 021

9. Castañer E, Gallardo X, Rimola J, Pallardó Y, Mata J, Perendreu J, Martin C, Gil D (2006) Congenital and acquired pulmonary artery anomalies in the adult: radiologic overview. Radiographics 26(2):349-371

10. Ten Harkel AD, Blom NA, Ottenkamp J (2002) Isolated unilateral absence of a pulmonary artery: a case report and review of the literature. Chest 122(4):1471-1477. https://doi.org/10.1378/chest.122.4.1471

11. Anand SH, Jasper A, Mani SE, Joseph E, Mathai J (2015) Proximal interruption of the pulmonary artery: a case series. J Clin Diagn Res 9(12):4-6. https://doi.org/10.7860/JCDR/2015/16198.6980

12. Bouros D, Pare P, Panagou P, Tsintiris K, Siafakas N (1995) The varied manifestation of pulmonary artery agenesis in adulthood. Chest 108(3):670-676

13. Presbitero P, Bull C, Haworth SG, de Leval MR (1984) Absent or occult pulmonary artery. Br Heart J 52(2):178-185

14. Kadir IS, Thekudan J, Dheodar A, Jones MT, Carroll KB (2002) Congenital unilateral pulmonary artery agenesis and aspergilloma. Ann Thoracic Surg 74(6):2169-2171

15. Griffin N, Mansfield L, Redmond KC, Dusmet M, Goldstraw P, Mittal TK, Padley S (2007) Imaging features of isolated unilateral pulmonary artery agenesis presenting in adulthood: a review of four cases. Clin Radiol 62(3):238-244

16. Morosetti D, Di Stefano C, Mondillo M, Pensabene MC, De Corato L, Bizzaglia M, Di Martino A, Floris R (2019) Right-sided aortic arch with mirror image branching and situs solitus: a case of a 79 years old woman. Radiol Case Rep 14(10):1246-1251. https://doi.org/10.1016/j.radcr.2019.07.014

\section{Publisher's Note}

Springer Nature remains neutral with regard to jurisdictional claims in published maps and institutional affiliations. 